\title{
HIF-1a IS POSITIVELY ASSOCIATED WITH SCAVENGER RECEPTORS LOX-1, CXCL16 AND MSR1 IN ADIPOSE TISSUE
}

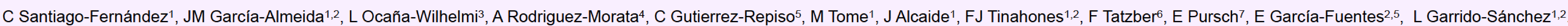

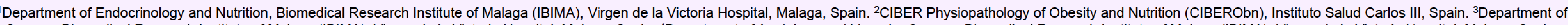

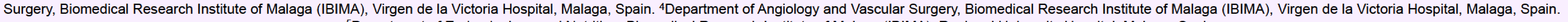
DDepartment of Endocrinology and Nutrition, Biomedical Research Institute of Malaga (IBIMA), Regional University Hospital, Malaga, Spain.

${ }^{6}$ Medical University of Graz, Centre of Molecular Medicine, Institute of Pathophysiology \& Immunology, Graz, Austria. ${ }^{-U n i v e r s i t y ~ o f ~ A p p l i e d ~ S c i e n c e s ~ T e c h n i k u m ~ W i e n, ~ I n s t i t u t e ~ o f ~ B i o c h e m i s t r y, ~ V i e n n a, ~ A u s t r i a . ~}$

\section{Introduction}

HIF-1a, a hypoxia marker, is an important factor for transcriptional regulation of cell metabolism and the adaptation to cellular stress. It modulates the function of phagocytic cells by stimulating surface receptors such as scavenger receptors. But little is known on their relationship in adipose tissue, whose increase has been associated with an increased risk of atherosclerosis. The aim of this study is to analyze in adipose tissue the association between mRNA expression levels of HIF-1a and different scavenger receptors, and their relationship with the presence of obesity.

\section{Design}

We study in 21 non-obese and 26 morbidly obese patients (MO) the mRNA gene expression levels of HIF-1a and different scavenger receptors (lectin-like oxLDL-1 (LOX-1), macrophage scavenger receptor 1 (MSR1) and chemokine (C-X-C motif) ligand 16 (CXCL16)) in visceral (VAT) and subcutaneous adipose tissue (SAT). We also analyzed the effect of hypoxia on the VAT mRNA expression of differents scavenger receptors (LOX-1, MSR1 and CXCL16).

\section{Results}

LOX-1 and HIF-1 $\alpha$ mRNA gene expressions are increased in VAT from MO patients ( $p=0.025$ vs. $p=0.003$, respectively), but not in SAT (Figure 1 and 2 ). MSR-1 and CXCL16 mRNA gene expression levels are higher in MO patients in VAT and SAT (VAT: $p=0.001$ vs. $p<0.001$, respectively, and SAT: $p<0.001$ vs. $p<0.001$, respectively) (Figure 3 and 4). HIF-1a mRNA gene expression in VAT has positively correlated with the weight, body mass index and waist circumference, and negatively with serum HDL and adiponectin levels. HIF-1 a mRNA gene expression is positively associated with MSR1 and CXCL16 in VAT and SAT, and positively with LOX-1 mRNA expression only in VAT. VAT explants incubated in hypoxia showed reduced MSR1 $(p=0.007)$ and increased LOX-1 $(p=0.005)$ and CXCL16 ( $p=0.005)$ mRNA expression (Figure 5).

Table 1. Anthropometric and biochemical variables in the non-obese and morbidly obese subjects.

\begin{tabular}{|c|c|c|}
\hline & $\begin{array}{c}\text { NON-OBESE } \\
(n=21)\end{array}$ & $\begin{array}{c}\text { MORBIDLY OBESE } \\
(n=26)\end{array}$ \\
\hline Sex (male/female) & $9 / 12$ & 9/17 \\
\hline Age (years) & $44.67 \pm 16.10$ & $38.96 \pm 10.54$ \\
\hline Weight (Kg) & $63.26 \pm 9.56$ & $148.20 \pm 28.39 \pi$ \\
\hline BMI (kg/m²) & $22.52 \pm 1.74$ & $56.15 \pm 8.64 \pi$ \\
\hline Waist (cm) & $82.17 \pm 9.97$ & $141.96 \pm 17.44^{\pi}$ \\
\hline Hips (cm) & $96.57 \pm 5.49$ & $155.61 \pm 14.88$ \\
\hline TAS (mmHg) & $116.10 \pm 23.51$ & $138.47 \pm 19.36^{*}$ \\
\hline TAD (mmHg) & $79.38 \pm 17.07$ & $82.47 \pm 13.18$ \\
\hline Glucose (mg/dL) & $89.48 \pm 14.03$ & $94.12 \pm 11.78$ \\
\hline Cholesterol (mg/dL) & $202.86 \pm 34.44$ & $195.23 \pm 41.79$ \\
\hline Triglycerides (mg/dL) & $124.10 \pm 100.27$ & $136.61 \pm 78.50$ \\
\hline HDL-c (mg/dL) & $55.81 \pm 13.54$ & $43.48 \pm 11.01^{*}$ \\
\hline LDL-c (mg/dL) & $121.47 \pm 26.91$ & $122.49 \pm 29.64$ \\
\hline Insulin $(\mu \mathrm{IU} / \mathrm{ml})$ & $13.56 \pm 9.56$ & $23.20 \pm 14.15^{*}$ \\
\hline HOMA-IR & $3.00 \pm 2.15$ & $5.50 \pm 3.49^{*}$ \\
\hline Leptin (ng/mL) & $14.85 \pm 15.58$ & $68.63 \pm 35.06 \pi$ \\
\hline Adiponectin $(\mu \mathrm{g} / \mathrm{mL})$ & $25.41 \pm 16.04$ & $9.63 \pm 4.46 \pi$ \\
\hline
\end{tabular}

The results are given as the mean \pm standard deviation. BMI: body mass index. HOMA-IR: homeostasis model assessment of insulin resistance index. TAS: systolic artery tension. TAD: diastolic artery tension. Significant diferrences between non-obese and morbidly obese patients $(* p<0.05 ; \Uparrow p<0.001)$

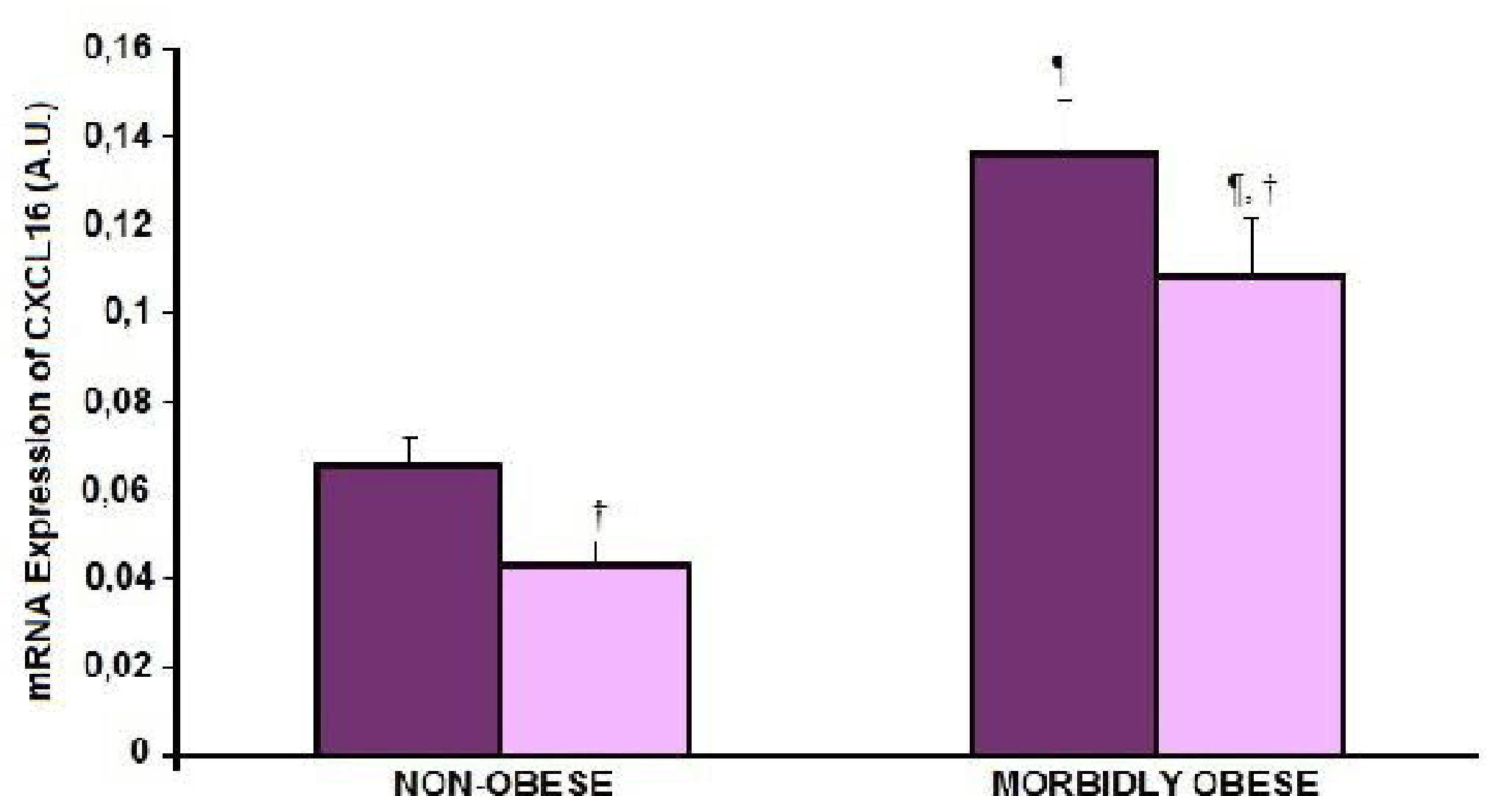

Figure 3. mRNA expression of CXCL16 in human visceral (VAT) $(\square)$ and subcutaneous adipose tissue (SAT) $(\square)$ in the non-obese and morbidly obese subjects. The results are given as the mean \pm SEM. TDifferences between non-obese and morbidly obese $(p<0.001)$. HDifferences between VAT and SAT in the two groups $(p<0.05)$

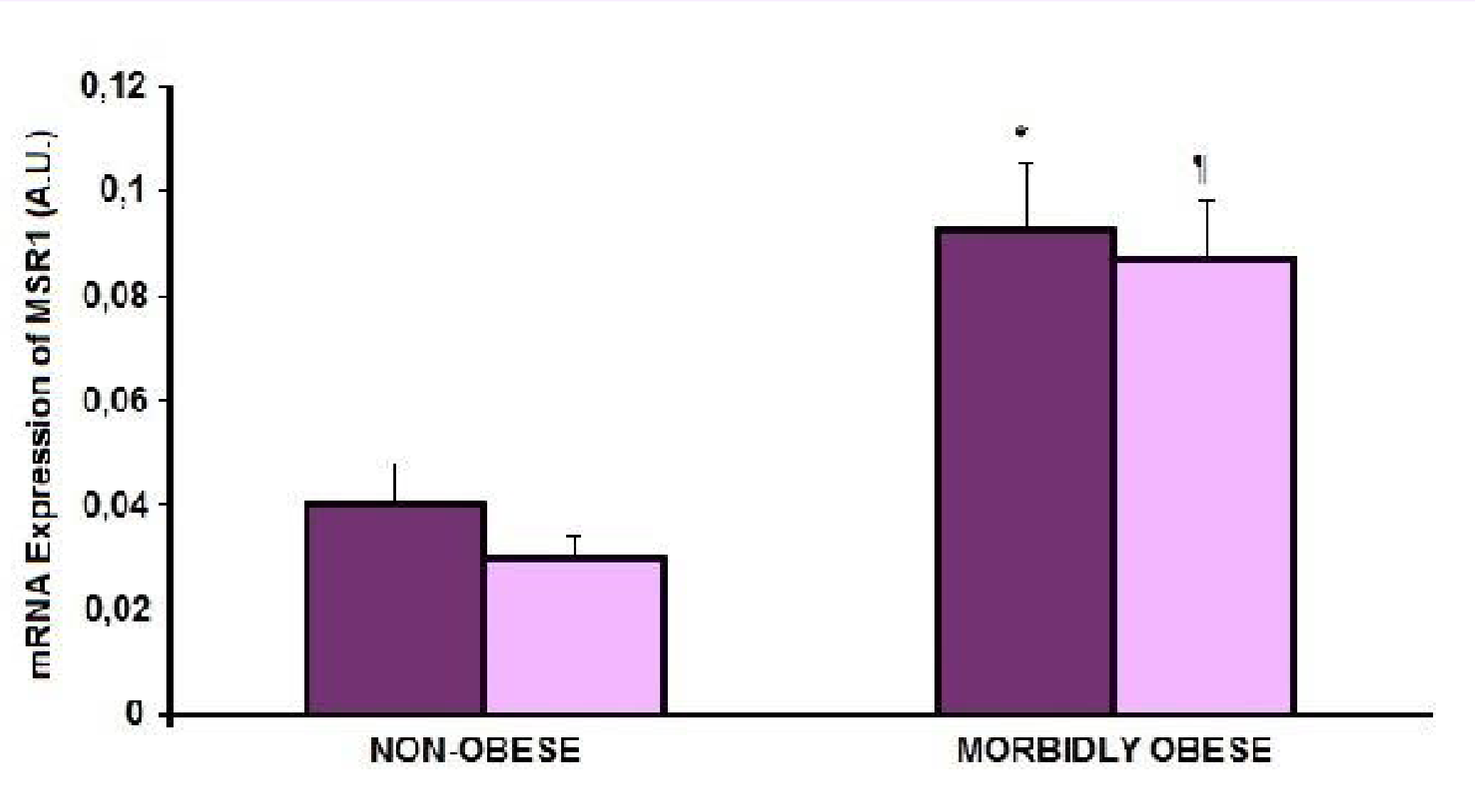

Figure 4. mRNA expression of MSR1 in human visceral (VAT) ( $\square$ ) and subcutaneous adipose tissue (SAT) ( $\square$ ) in the non-obese and morbidly obese subjects. The results are given as the mean \pm SEM. Differences between nonobese and morbidly obese: ${ }^{*} p<0.05 ; \uparrow p<0.001$

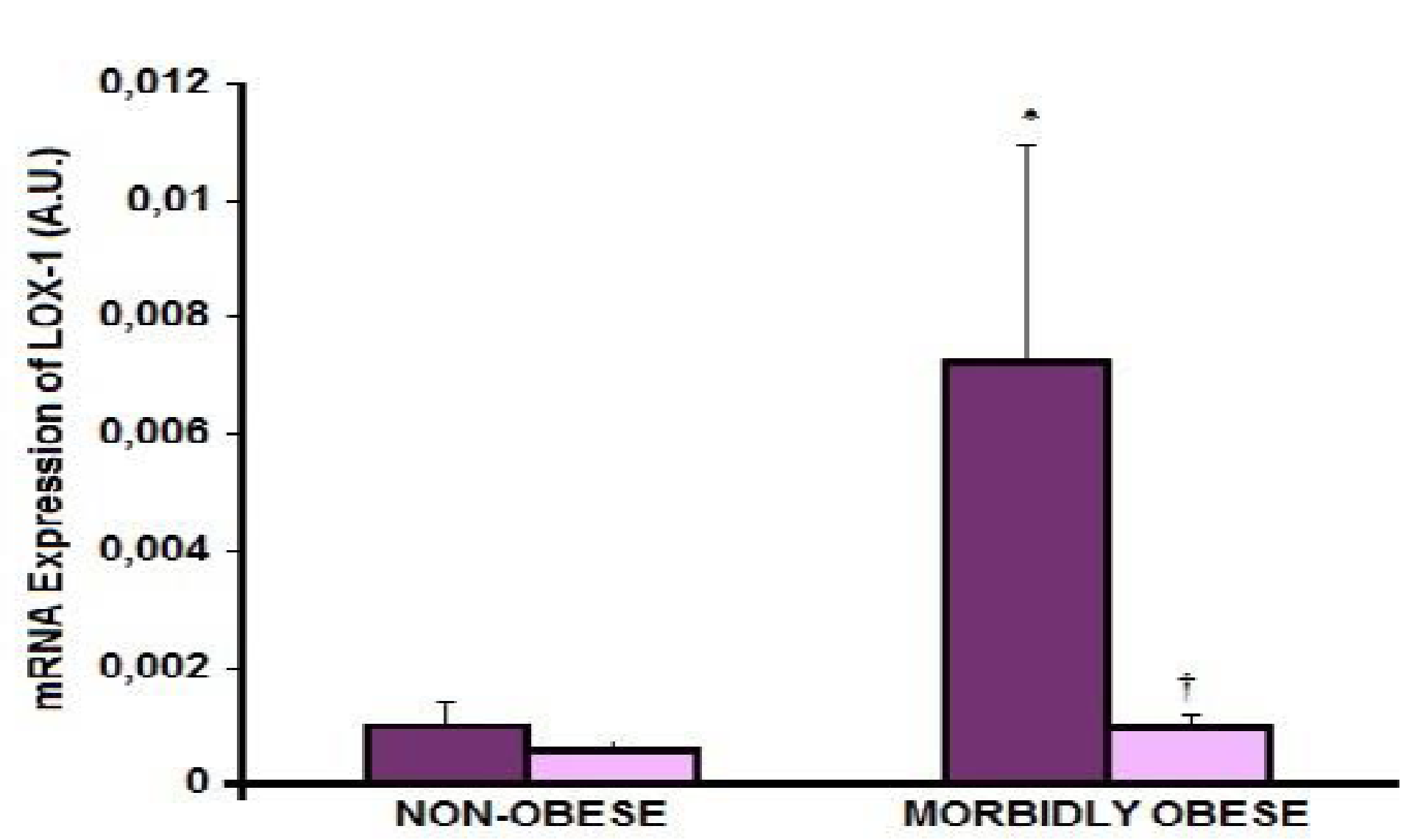

Figure 1. mRNA expression of LOX-1 in human visceral (VAT) ( $\square$ ) and subcutaneous adipose tissue (SAT) ( $)$ in the non-obese and morbidly obese subjects. The results are given as the mean \pm SEM. ${ }^{*}$ Differences between non-obese and morbidly obese $(p<0.05)$. †Differences between VAT and SAT in the morbidly obese patients $(p<0.05)$

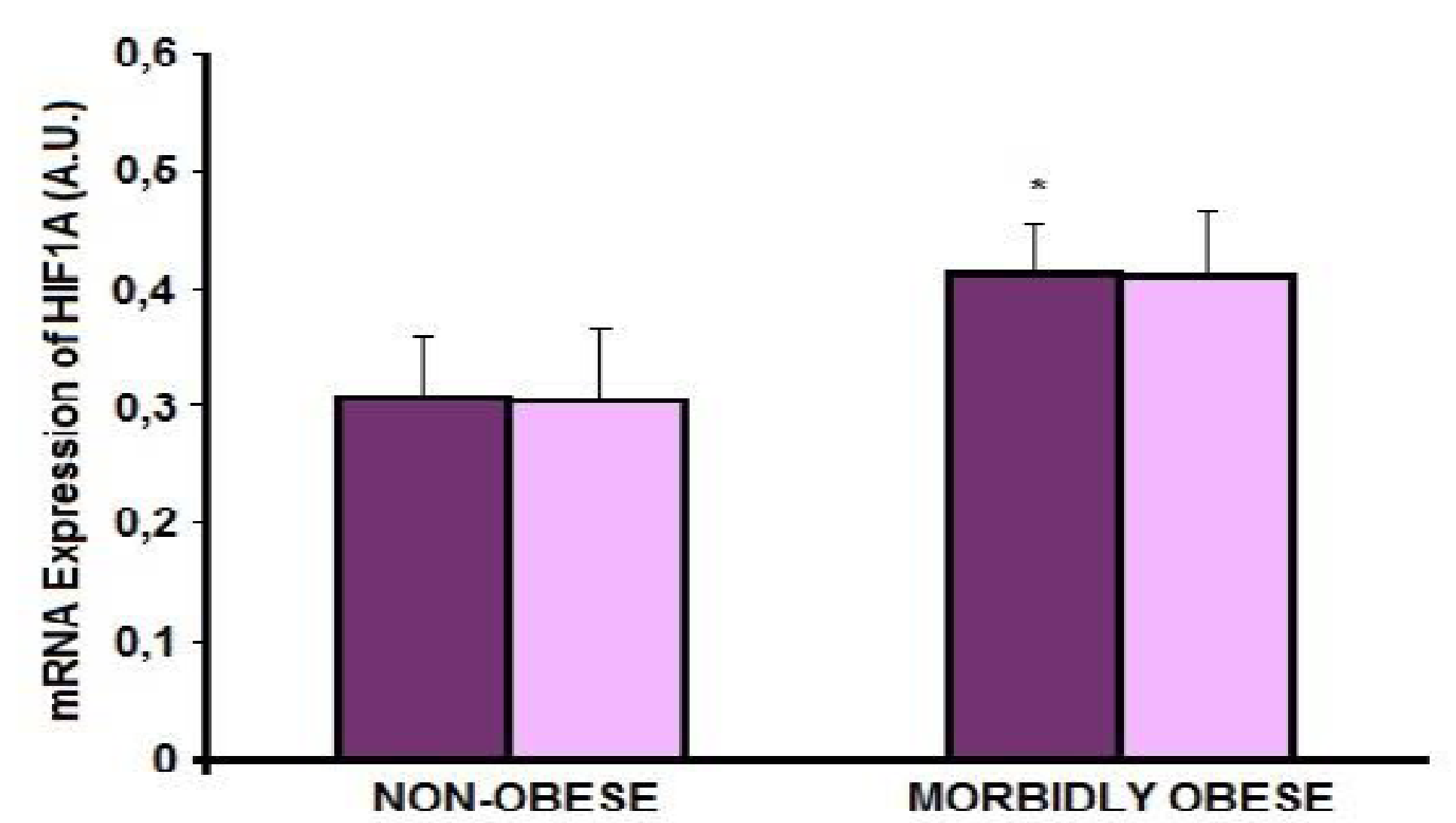

Figure 2. mRNA expression of HIF1a in human visceral (VAT) ( $\square$ ) and subcutaneous adipose tissue (SAT) $(\square)$ in the non-obese and morbidly obese subjects. The results are given as the mean \pm SEM. *Differences between non-obese and morbidly obese $(p<0.05)$

\section{I}

\section{Conclusions}

In this study we demonstrate the positive association in the adipose tissue between the mRNA gene expression level of HIF-1a, a hypoxia marker, and different scavenger receptors. Hypoxia alters the mRNA expression of different scavenger receptors in human VAT.

\section{Acknowledgments}

This work was supported in part by grants from Instituto de Salud Carlos III (CP13/00188), Spain. This study has been co-funded by FEDER funds.

\section{3--EP}

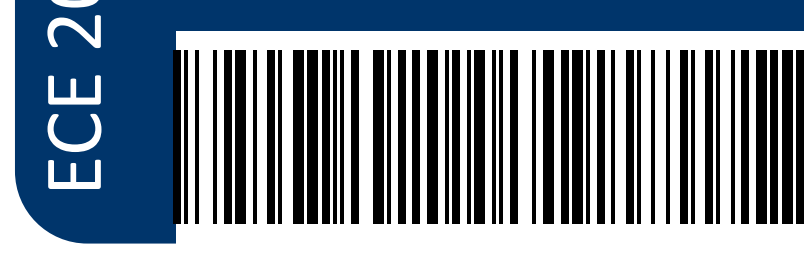
Obesity epción Santiago-Fernandez 